\title{
NASA launch heralds fresh wave of comet exploration
}

Tony Reichhardt, Washington

The planned launch of NASA's CONTOUR (Comet Nucleus Tour) spacecraft in Florida on 1 July will herald a period of intense comet exploration, the like of which has not been since an armada of spacecraft visited Halley's Comet in 1986.

Between now and 2006, four spacecraft will either set off for, or return data from, the vicinity of a comet, capturing close-up images as well as dust and gas samples.

Three NASA missions - CONTOUR, Stardust and Deep Impact - as well as the Rosetta mission, launched by the European Space Agency (ESA), will "take the investigation of comets to a completely different stage", says Hal Weaver of Johns Hopkins University in Baltimore, Maryland. Spacecraft cameras and spectrometers are far better than they were 16 years ago, points out CONTOUR's principal investigator, Joseph Veverka of Cornell University in Ithaca, New York, and are better suited to answering questions about the chemistry and formation of comets.

CONTOUR will pass through the comas - clouds of dust and gas - that surround the icy nuclei of the Encke and Schwassmann-Wachmann 3 (S-W3) comets in 2003 and 2006, respectively.

The craft's mass spectrometer will measure the ratio of hydrogen to deuterium in comets, revealing whether they delivered water to Earth early in the planet's history.

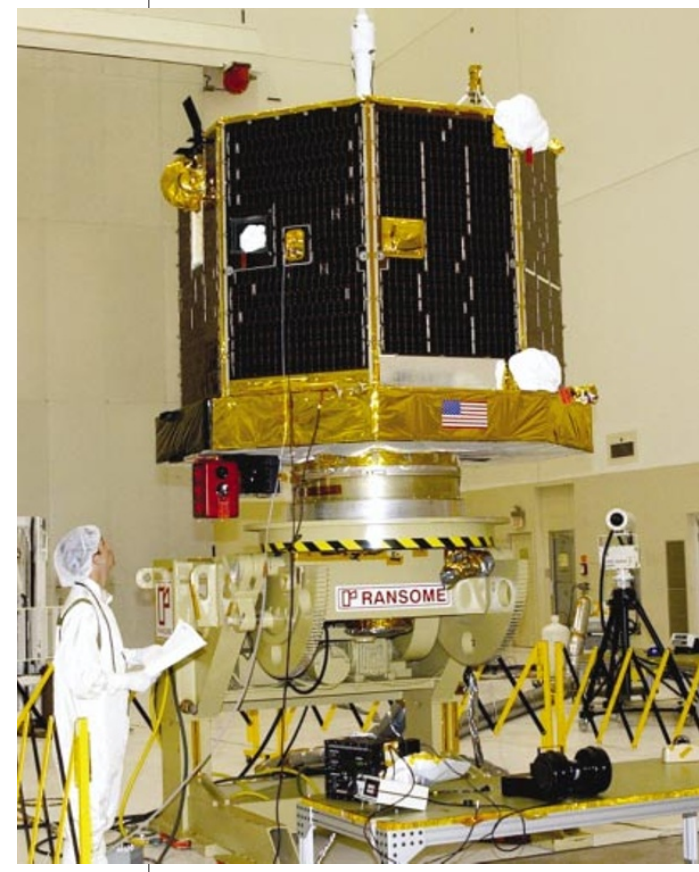

Exploring new frontiers: the CONTOUR craft will pass close to the Encke and S-W3 comets.
Ground-based studies of two comets that recently passed close to Earth, Hale-Bopp and Hyakutake, suggest that they may not have. But both of these originated in the distant Oort Cloud that surrounds the Solar System, and may not have the same chemical make-up as Encke, S-W3 and other shortperiod comets, which came from the much nearer Kuiper belt outside Pluto's orbit.

Only two cometary nuclei have been photographed at close range - Halley's Comet, by ESA's Giotto spacecraft in 1986, and Borrelly, last year by NASA's Deep Space 1. Neither was able to show conclusively whether the comets' nuclei were coherent or loose "rubble piles", says Weaver. But CONTOUR's images will have 10 times the resolution of Deep Space 1's, and 25 times that of Giotto's.

NASA's Deep Impact probe, which is scheduled to launch in 2004 , will go a step further, smashing into the comet Tempel 1 a year later to study the material kicked up by the impact. Stardust, which has already been launched, will bring cometary dust back from the comet P/Wild 2 in 2006.

But the most expensive and ambitious of the new cometary explorers is ESA's US\$700million Rosetta, which was a partnership with NASA before the US agency withdrew in 1996 (see Nature 383, 469; 1996). Rosetta will be launched next January and reach the comet Wirtanen in 2011, where it will place one probe in orbit and land another on the nucleus. The mission aims to observe the comet as it heats up on its approach to the Sun and begins to spew gas and dust.

If Rosetta is the most thorough investigation on the drawing board, CONTOUR may be the most flexible. It was born, says Veverka, out of US scientists' frustration at not mounting a large comet mission in the 1980s and 1990s, despite several aborted NASA plans. By design, CONTOUR's orbit will bring the craft looping past the Earth once a year.

When it finishes its primary mission, it can easily be targeted to meet with other known comets, including d'Arrest, which is younger than Encke but older than S-W3. The ideal scenario would be for a new comet to be thrown towards Earth from the Oort Cloud, giving scientists the chance to study a different class of object at close quarters.

Any encounters after those with Encke and S-W3 would need to be approved by NASA. CONTOUR's total project cost was US $\$ 159$ million, half the price of a typical mission in NASA's Discovery series of planetary probes. So comet specialists are hoping that the agency will be generous if they ask it to prolong CONTOUR's life beyond 2006.

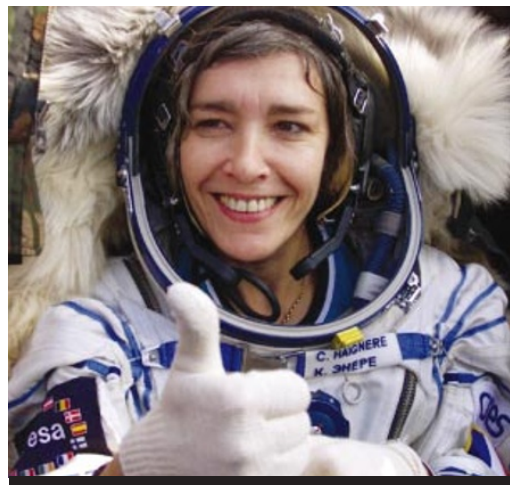

Thumbs up: Claudie Haigneré's appointment is broadly welcomed by French researchers.

Astronaut lands top research post in new French government

\section{Sally Goodman, Paris}

The astronaut Claudie Haigneré has been named minister for research in France's new centre-right government.

Haigneré's scientific background includes a medical degree and $\mathrm{PhD}$ in neuroscience. Haigneré the astronaut is a familiar face to the French public, having first gone into space in 1996 to the Mir space station. Last October she spent ten days on the International Space Station.

Her high profile has helped to persuade researchers that she is suitable for the job despite her lack of political experience. "It's an original and courageous choice of minister," says Pierre Tambourin, director of the Genopole science park in Evry, near Paris. "I think she will defend science well."

Haigneré will have clear authority to tackle the most pressing problems facing French research. Jean-Pierre Raffarin, the new prime minister, belongs to the same party as president Jacques Chirac, ending the power-sharing between president and parliament that previously stifled reforms.

Improving the attractiveness of scientific careers and increasing the competitiveness of French research are likely to be high on her list of challenges.

Chirac has promised that research will be a priority. "We hope he sticks to his word," says Tambourin. "Researchers have not forgotten previous occasions when Chirac was in power when he reduced the research budget to fund other priorities."

Haigneré's research responsibilities will be overseen by Luc Ferry, head of the new superministry of youth, education and research (see Nature 417, 214; 2002). But Ferry will be in charge of higher education - even though most labs run by the CNRS, France's basic-research agency, are hosted by universities. 